OPEN ACCESS

Edited by:

Thomas Efferth,

University of Mainz, Germany

Reviewed by:

Victor Kuete,

University of Dschang, Cameroon

Xiao Yu Tian,

The Chinese University of Hong Kong,

China

*Correspondence:

Umar Faroog

umarf@ciit.net.pk;

Ajmal Khan

ajmalkhan@ciit.net.pk;

Afsar Khan

afsarkhar@ciit.net.pk

Specialty section:

This article was submitted to

Ethnopharmacology,

a section of the journal

Frontiers in Pharmacology

Received: 05 June 2015 Accepted: 03 November 2015

Published: 23 November 2015

Citation:

Sarwar R, Farooq U, Khan A, Naz S, Khan S, Khan A, Rauf A, Bahadar H

and Uddin R (2015) Evaluation

of Antioxidant, Free Radical

Scavenging, and Antimicrobial Activity

of Quercus incana Roxb.

Front. Pharmacol. 6:277.

doi: 10.3389/fphar.2015.00277

\section{Evaluation of Antioxidant, Free Radical Scavenging, and Antimicrobial Activity of Quercus incana Roxb.}

\author{
Rizwana Sarwar ${ }^{1}$, Umar Farooq ${ }^{1 *}$, Ajmal Khan ${ }^{1 *}$, Sadia Naz', Sara Khan ${ }^{1}$, Afsar Khan ${ }^{1 *}$, \\ Abdur Rauf', Haji Bahadar ${ }^{3}$ and Reaz Uddin ${ }^{4}$ \\ ${ }^{1}$ Department of Chemistry, COMSATS Institute of Information Technology, Abbottabad, Pakistan, ${ }^{2}$ Department of Geology, \\ University of Swabi, Anbar, Pakistan, ${ }^{3}$ Department of Pharmacy, Kohat University of Science and Technology, Kohat, \\ Pakistan, ${ }^{4}$ Dr. Panjwani Center for Molecular Medicine and Drug Research, International Center for Chemical and Biological \\ Sciences, University of Karachi, Karachi, Pakistan
}

Considering the indigenous utilization of Quercus incana Roxb., the present study deals with the investigation of antioxidant, free radical scavenging activity, total phenolic content, and antimicrobial activity of $Q$. incana Roxb. In vitro antioxidant activity of the plant fractions were determined by 1,1-diphenyl-2-picrylhydrazyl and nitric oxide scavenging method. Total phenolic contents were determined by gallic acid equivalent and antimicrobial activities were determined by agar well diffusion method. It was observed that $Q$. incana Roxb. showed significant antibacterial activity against Grampositive and Gram-negative bacteria. $n$-Butanol fraction showed maximum activity against Micrococcus leuteus with $19 \mathrm{~mm}$ zone of inhibition. $n$-Butanol fraction of $Q$. incana Roxb. showed immense antifungal activity against Aspergillus niger (32 $\mathrm{mm} \pm 0.55$ ) and $A$. flavus (28 $\mathrm{mm} \pm 0.45$ ). Similarly $n$-butanol fraction showed relatively good antioxidant activity with $I_{50}$ value of $55.4 \pm 0.21 \mu \mathrm{g} / \mathrm{mL}$. The $\mathrm{NO}$ scavenging activity of ethyl acetate fraction $\left(\mathrm{IC}_{50}=23.21 \pm 0.31 \mu \mathrm{g} / \mathrm{mL}\right)$ was fairly good compared to other fractions. The current study of $Q$. incana Roxb. suggests the presences of synergetic action of some biological active compounds that may be present in the leaves of medicinal plant. Further studies are needed to better characterize the important active constituents responsible for the antimicrobial, antioxidant and free radical scavenging activity.

Keywords: Quercus incana Roxb., antimicrobial, free radical scavenging, antioxidant activity, oxidative stress

\section{INTRODUCTION}

Oxidative damage is a major source of many illnesses; as free radicals, and reactive oxygen species (ROS) attacks cell macromolecules. Antioxidants play key role in preventing cell being injured by ROS by counter acting these free radicals (Lai et al., 2001). Antioxidants derived from plants provide protection to cell by scavenging free oxygen radical through offsetting ROS.

Abbreviations: DPPH, 1,1-diphenyl-2-picrylhydrazyl; GAE, gallic acid equivalent; RSA, radical scavenging activity; SNP, sodium nitroprusside. 


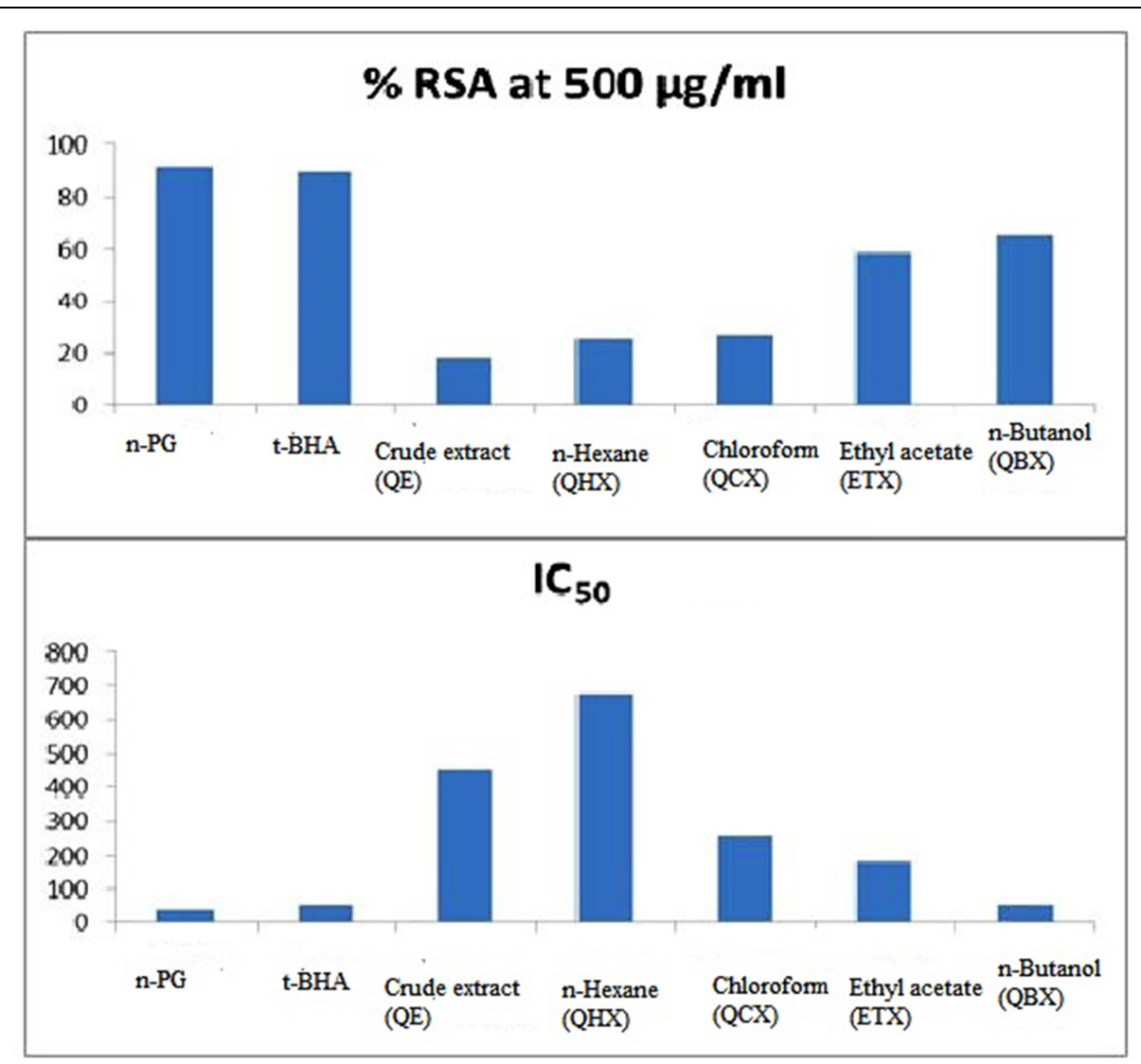

FIGURE 1 | Antioxidant activity in \% RSA and IC $_{50}$.

This has been made possible due to the presence of certain bioactive substances, such as phenolic compounds, flavonoids, and essential oils, rendering plants with antioxidant activity (Liu, 2003). Nitric oxide (NO) acts as neurotransmitter through exerting their effect on different body operations, such as neurotransmission, synaptic plasticity, vasodilation, and CNS memory (Shibuki and Okada, 1991; Bredt and Snyder, 1994). Besides key role of $\mathrm{NO}$ in facilitating normal function, it has been observed that NO has been associated with pathophysiologic states like neurodegenerative and Alzheimer's disease. Excessive release of NO in the body can cause DNA fragmentation, cell damage, and neuronal cell death (Moncada et al., 1991; Dawson et al., 1992). Plants can play crucial role in reducing amount of NO through their efficient NO scavenging activity.

In order to amplify the data corroborating potent plant that may be exploited as antimicrobial and antioxidant agent, the Quercus incana Roxb. was selected to be assessed for possible medicinal action. Q. incana Roxb. belongs to family Fagaceae, represented by 8 genera and 900 species, abundantly found in the temperate regions of the world. In Pakistan, this family is represented by two genera namely Castana and Quercus. Quercus is represented by six species in Pakistan most of which are wild, distributed in northern temperate regions. The wood of this genus is durable, tough and is widely used for shipbuilding, flooring, furniture, railroad ties, barrels, tool handles, etc. (Adonizio et al., 2006). Due to high tannin content in Quercus species, it is used in tanning leather. The barrels made from Quercus wood are used to hoard wine and it also impart special flavor to wine. As far as its medicinal characteristics are concerned, this genus has been found to possess antioxidant, antifungal, antibacterial, and anticancer activities (Ge et al., 2008).

In folk medicine this genus is especially significant as hemostatic, in the treatment of gastrointestinal disorders (Kaur et al., 2004), inflammations of the oral, genital, and anal mucosa and externally against inflammation of the skin (Konig et al., 1994). Polar fractions of the leaves, bark, wood, and galls have shown antibacterial and antiinflammatory activities (Ito et al., 2002; Hamid et al., 2005; Berahou et al., 2007) that explain their ethno-pharmacological uses. The ethanolic extract of $Q$. leucotrichophora exhibited a potent antimicrobial activity against Staphylococcus aureus, Pseudomonas auroginosa, Bacillus subtilis, and Escherichia coli (Sati et al., 2011).

Analysis on physiochemical constituent of this genus has shown that plants belonging to genus Quercus possess a rich load of lignins, hydrolysable tannins, ellagitannins, flavanoellagitannins, catechins, flavan and proanthocyanidin glycosides, flavonoids and simple phenols, and proanthocyanidin glycosides (Nonaka et al., 1985; Karioti et al., 2009). 


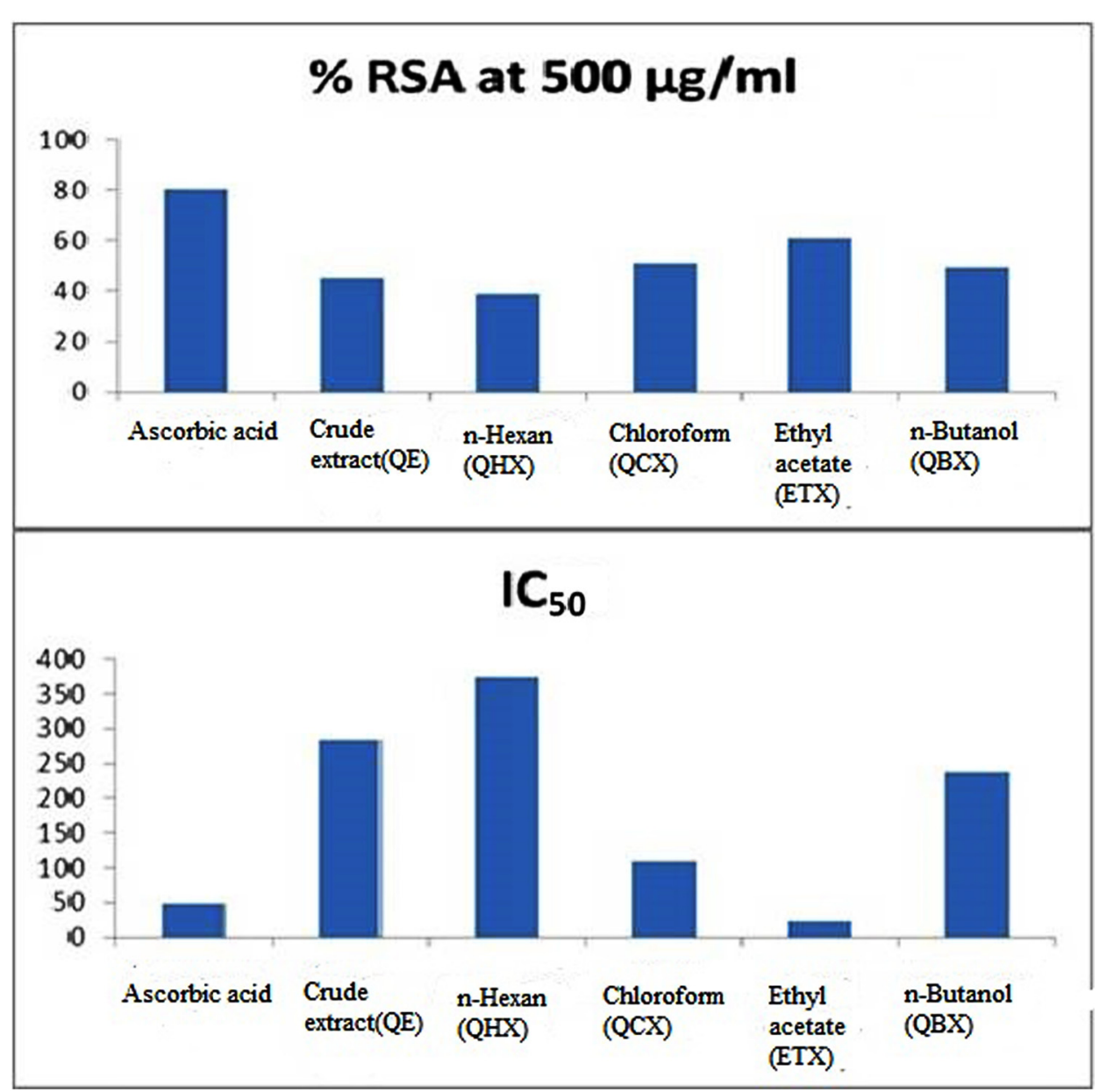

FIGURE 2 | NO activity in \% RSA and $I_{50}$ values.

Quercus incana Roxb. was used as astringent (Hussain and Ghani, 2008), antidiarrheal, diuretic, and to treat asthma (Haq et al., 2011), antipyretic, anti-rheumatism, wound healing, immature abscesses, antidiabetic, and anti-arthritic (Shinwari and Khan, 2000). Considering the medicinal importance of genus Quercus, the Q. incana Roxb. was selected for the possible antimicrobial, antioxidant activity. and NO scavenging activity.

\section{MATERIALS AND METHODS}

\section{Plant}

Leaves of Q. incana Roxb. were collected from District Abbottabad in May 2011. It was shade dried (16 kg) and soaked in methanol, then extracted on rotary evaporator. Crude extract (620 g) obtained as a result of extraction was partitioned between n-hexane (160 g), chloroform (138 g), ethyl acetate (75 g), $n$-butanol (105 g), and aqueous fraction (110 g). Fractions were subjected to antioxidant, free RSA, and antimicrobial screening by using different methods. Total phenolic content of fractions was also calculated.

\section{Antioxidant Activity}

Free RSA of all fractions of plant were measured by DPPH method (Choudhary et al., 2008). $100 \mathrm{mM}$ concentrated solution of DPPH was prepared in high-performance liquid chromatography (HPLC) grade methanol and plant fractions were dissolved in dimethyl sulfoxide (DMSO). Plant fractions were mixed with DPPH and allowed to react for half an hour at $37^{\circ} \mathrm{C}$. In this assay two standard $n$-Propyl gallate and 3-t-butyl-4hydroxyanisole were used. Five dilutions for each fraction along with standard were tested and experiment was repeated triplicate. After incubation absorbance was measured using microplate reader (Bio-Tek Elx800 TM, Instruments, Inc., USA). Percent RSA (\% RSA) of samples was determined, while DMSO used as control group using the following formula:

$$
\% \mathrm{RSA}=100-\frac{[\text { Absorbance of test compounds] }}{\text { Absorbance of control }} \times 100 .
$$

\section{NO Scavenging Activity}

Sodium nitroprusside was used for generation of $\mathrm{NO}$ and it was measured by the Griess reagent (1\% sulphanilamide, $0.1 \%$ 


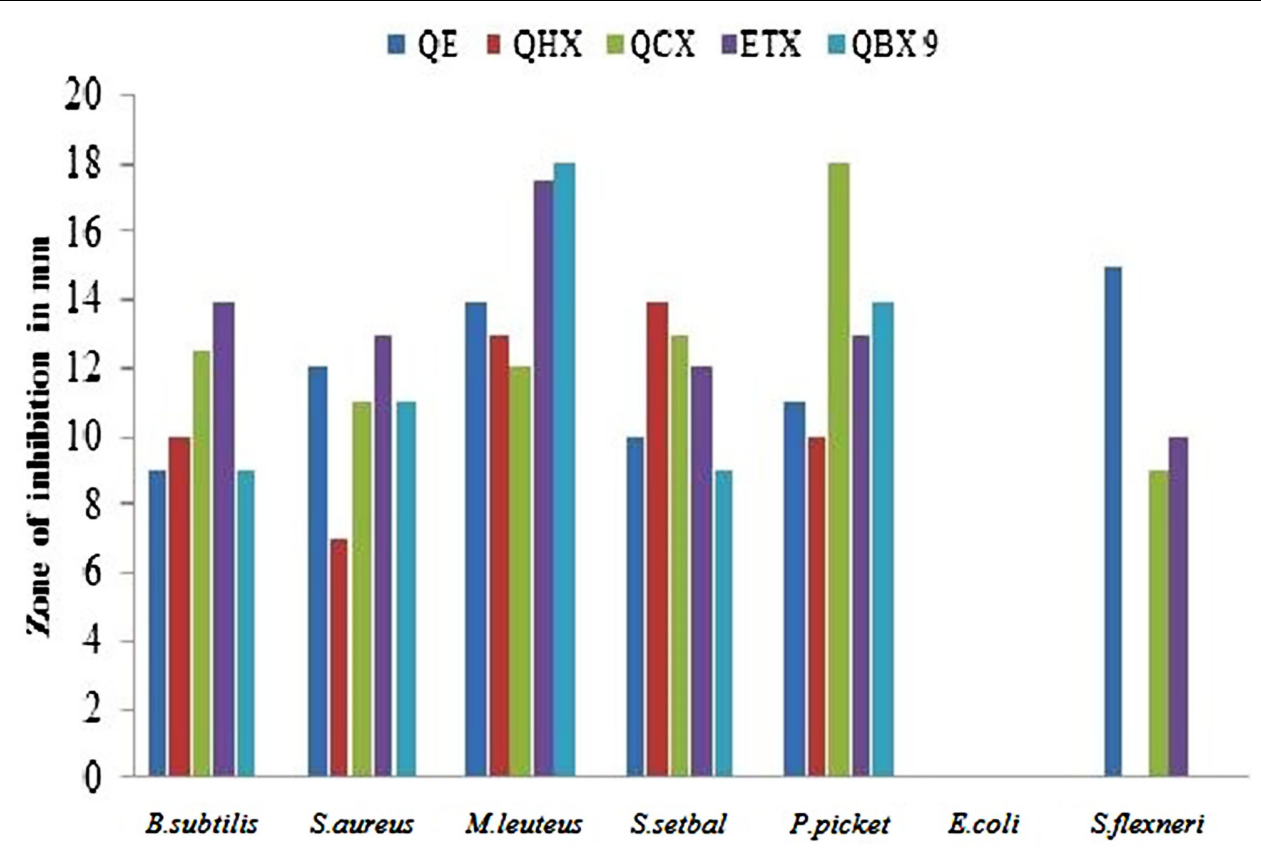

FIGURE 3 | Antibacterial activity of fractions against bacterial strains. B. subtilis, Bacillus subtilis; S. aureus, Staphylococcus aureus; M. leuteus, Micrococcus leuteus; S. setuba I, Salmonella setubal; P. pickettii, Pseudomonas pickettii; E. coli, Escherichia coli; S. flexneri, Sigella flexneri.

naphthylethylenediamine dichloride (NED), and 3\% phosphoric acid). SNP spontaneously generates $\mathrm{NO}$ in aqueous solution at physiological pH (Marcocci et al., 1994) results in production of nitrite ions by its interaction with oxygen, whose estimation is done by Griess reagent. Scavengers of NO compete with oxygen leading to reduced production of NO. Different concentrations $(100-1000 \mu \mathrm{g} / \mathrm{mL})$ of plant fractions dissolved in ethanol and water was mixed with SNP $(10 \mathrm{mM})$ in phosphate buffer saline (PBS) and incubated at $25^{\circ} \mathrm{C}$ for $3 \mathrm{~h}$. The samples were then reacted with griess reagent, and absorbance was recorded at $546 \mathrm{~nm}$ of chromophore formed as result of diazotization of nitrite with sulphanilamide, and subsequent coupling with NED was done using microplate reader and compared to positive control which in this case was ascorbic acid treated in same way to Griess reagent. The ethanol was used as control using the following formula:

$$
\text { Nitric oxide scavenged }(\%)=\frac{\left(A_{\text {control }}-A_{\text {test }}\right)}{A_{\text {control }}} \times 100 \text {. }
$$

\section{Total Phenolic Contents of Fractions}

Total phenolic content of extract was determined by spectroscopic method using Folin-Ciocalteu reagent (diluted 10-fold) and gallic acid as standard (Osawa and Namiki, 1981). Ethanol solution of gallic acid ( $1 \mathrm{~mL} ; 0.025-0.400 \mathrm{mg} / \mathrm{mL})$ was mixed with $5 \mathrm{~mL}$ Folin-Ciocalteu reagent (diluted tenfold) and sodium carbonate $(4 \mathrm{~mL}, 0.7 \mathrm{M})$ to give calibration curve. Standard curve was drawn after measuring absorbance at $765 \mathrm{~nm} .1 \mathrm{~mL}$ of plant crude fraction $(5 \mathrm{~g} / \mathrm{L})$ was also mixed with the above reagents, and left for $30 \mathrm{~min}$. The total phenolic content was analyzed against gallic acid standard curve by taking absorbance. Readings were taken in triplicate. The total phenolic of all fractions in GAE were calculated by the following formula:

$$
T=\frac{C V}{M}
$$

Where $\mathrm{T}$ is the total phenolic contents, $\mathrm{mg} / \mathrm{g}$ of fraction, in GAE; $C$ is the concentration of gallic acid established from the calibration curve, $\mathrm{mg} / \mathrm{mL} ; V$ is the volume of the fraction, $\mathrm{mL}$; and $M$ is the weight of the fraction (g).

\section{Antibacterial Activity}

Each fractions of Q. incana Roxb. were tested separately, employing agar well diffusion method (Harit et al., 2013; Bag and Chattopadhyay, 2015; Zhou et al., 2015). The medium was sterilized by autoclaving at $120^{\circ} \mathrm{C}$ and $20 \mathrm{ml}$ of the agar medium was aseptically transferred into each sterilized Petri plate, which was solidified at room temperature. Bacterial strains were spread on agar plates with sterile cotton swab. A well of $6 \mathrm{~mm}$ diameter was made using a sterile cork borer. All fractions (3 mg) were dissolved in $1 \mathrm{~mL}$ of $20 \%$ DMSO solution. The $20 \mu \mathrm{L}$ of standard drug and fractions of the plant were poured in $6 \mathrm{~mm}$ diameter well. The assay plates were incubated at $37^{\circ} \mathrm{C}$ for $24 \mathrm{~h}$. The standard disk with ciprofloxacin (50 $\mu \mathrm{g}$ per disk) was used as a positive control for antibacterial activity and DMSO was used as negative control. Zone of inhibition was measured in $\mathrm{mm}$ and displayed in graph. 


\section{Antifungal Activity}

The antifungal activity was done by disk diffusion method (Bobbarala et al., 2009). Sabouraud dextrose agar plates were inoculated with each fungal strain by point inoculation. The filter paper disk (6 $\mathrm{mm}$ in diameter) impregnated with $1 \mathrm{mg} \mathrm{mL}-1$ of the fractions were placed on seeded plate. DMSO was used as solvent and was completely evaporated before applying to Petri plates. Blank disk impregnated with DMSO was used as negative control and nystatin was used as positive control. The activity was determined after $72 \mathrm{hrs}$ of incubation at $28^{\circ} \mathrm{C}$ and the diameters of the inhibition zones were measured in $\mathrm{mm}$.

\section{RESULTS AND DISCUSSION}

\section{Antioxidants}

The results of the free radical scavenging potential of fractions of Q. incana Roxb. was tested by DPPH method was presented in Figure 1. Antioxidant reacts with DPPH, which is a nitrogencentered radical with a characteristic absorption at $517 \mathrm{~nm}$ and converts it to DPPH, due to its hydrogen accepting ability at a very rapid rate (Yamaguchi et al., 1998).

The degree of discoloration indicates the scavenging potentials of the antioxidant present in fractions. Result showed that highest RSA was observed in $n$-butanol and ethyl acetate with \% inhibition of 64.85 and $58.89 \%$, respectively, while least in $n$-hexane fraction with $26.02 \%$ (Figure 1). Greater $\%$ inhibition of $n$ - butanol and ethyl acetate fractions were due to the presence of high polyphenolics, flavonoids, and tannins in the extracts. $\mathrm{IC}_{50}$ values were calculated using regression equation that showed inverse relationship between $\mathrm{IC}_{50}$ and percentage scavenging thus strongest DPPH radical scavenging was observed in $n$-butanol and ethyl acetate fraction with $\mathrm{IC}_{50}$ values of $55.4 \pm 0.21$ and $182.3 \pm 0.85 \mu \mathrm{g} / \mathrm{mL}$, respectively, while lowest was in $n$-hexane $677.8 \pm 0.67 \mu \mathrm{g} / \mathrm{mL}$. Standards used in this experiment, i.e., $n$-propyl gallate and 3-t-butyl-4hydroxyanisole showed \% RSA at $91.72 \%$ and $89.56 \%$ with IC $_{50}$ value of $40.13 \pm 0.74$ and $58.76 \pm 0.45 \mu \mathrm{g} / \mathrm{mL}$, respectively (Table 1).

\section{NO Scavenging Activity}

Nitric oxide is a potent pleiotropic mediator of physiological processes such as smooth muscle relaxation, inhibition of platelet aggregation, neuronal signaling, and regulation of

TABLE 1 | Antioxidant potential of Querus incana Roxb.

\begin{tabular}{lcc}
\hline Plant extracts & \% RSA at $\mathbf{5 0 0} \boldsymbol{\mu \mathbf { g } / \mathbf { m l }}$ & $\mathbf{I C}_{\mathbf{5 0}}(\boldsymbol{\mu} \mathbf{g} / \mathbf{m l})$ \\
\hline$n$-PG (Standard) & 91.72 & $40.13 \pm 0.74$ \\
$t$-BHA (Standard) & 89.56 & $58.76 \pm 0.45$ \\
Crude extract (QE) & 18.41 & $456.4 \pm 0.27$ \\
$n$-Hexane (QHX) & 26.02 & $677.8 \pm 0.67$ \\
Chloroform (QCX) & 27.24 & $258.8 \pm 1.03$ \\
Ethyl acetate (ETX) & 58.89 & $182.2 \pm 0.85$ \\
$n$-Butanol (QBX) & 64.85 & $55.4 \pm 0.21$
\end{tabular}

TABLE 2 | NO scavenging activity of Querus incana Roxb.

\begin{tabular}{lcr}
\hline Plant extracts & \% RSA at $\mathbf{5 0 0} \boldsymbol{\mu} \mathbf{g} / \mathbf{m l}$ & $\mathbf{I C}_{\mathbf{5 0}}(\boldsymbol{\mu} \mathbf{g} / \mathbf{m l})$ \\
\hline Ascorboic acid (Standard) & 80.42 & $48.88 \pm 0.74$ \\
QE & 45.02 & $282.87 \pm 0.08$ \\
QHX & 38.84 & $374.27 \pm 0.28$ \\
QCX & 50.94 & $108.63 \pm 0.78$ \\
ETX & 60.88 & $23.21 \pm 0.31$ \\
QBX & 49.17 & $238.17 \pm 0.16$ \\
\hline
\end{tabular}

Each value in the table was obtained by calculating the average of three experiments $\pm S D$.

cell mediated toxicity. It is a diffusible free radical which plays many important roles as an effector molecule in diverse biological systems (vasodilation, neuronal messenger, and antimicrobial and antitumor activities). Ascorbic acid used as the standard for NO radical scavenger in this analysis showed maximum activity with percentage RSA (\%RSA) of $80.42 \%$ with $\mathrm{IC}_{50}$ value $48.88 \pm 0.74 \mu \mathrm{g} / \mathrm{mL}$ (Table 2). Among all fractions ethyl acetate showed maximum RSA of $60.88 \%$ while $n$-hexane and crude fraction showed least activity with RSA of 38.84 and $45.02 \%$, respectively. The $\mathrm{IC}_{50}$ values calculated for each fraction of $Q$. incana Roxb. revealed that ethyl acetate, chloroform and $n$-butanol were highly active with $\mathrm{IC}_{50}$ value $23.21 \pm 0.31,108.63 \pm 0.78$, and $238.17 \pm 0.16 \mu \mathrm{g} / \mathrm{mL}$, respectively, while $n$-hexane showed least activity with $\mathrm{IC}_{50}$ value of $374.27 \pm 0.28 \mu \mathrm{g} / \mathrm{mL}$ (Figure 2).

\section{Total Phenolic Content}

Phenolic compounds, as secondary metabolites, are considered as the main actors for the antioxidant capacity of plants and have also many benefits on human health, as free radical scavenger. Phenolic compounds are also known as powerful chain breaking antioxidants. It is hard to estimate the real content of the phenolic compounds, due to the fact that the phenolic content are largely influenced by many factors, such as biotic and abiotic stress, senescence, cultivar, tissue, harvesting time, post-harvest treatment, and also extraction techniques. As reported in Table 3, result showed the significant total phenolic content in fractions of $Q$. incana Roxb. was observed.

$n$-Butanol fraction was found as the highest phenolic contents $89 \pm 3 \mathrm{mg} / \mathrm{g}$ fraction as compared to other fractions.

TABLE 3 | Total phenolic content of Q. incana Roxb.

\begin{tabular}{lc}
\hline Plant extracts & Total phenol (mg/g) \\
\hline QE & $165 \pm 6$ \\
QHX & $43 \pm 4$ \\
QCX & $56 \pm 7$ \\
ETX & $65 \pm 7$ \\
QBX & $89 \pm 3$
\end{tabular}

Each value in the table was obtained by calculating the average of three experiments $\pm S D$. 
TABLE 4 | Minimum inhibitory concentration (MIC) values of Q. incana Roxb. measured at different concentrations (mg/ml).

\begin{tabular}{|c|c|c|c|c|c|c|c|}
\hline \multirow[b]{2}{*}{ Plant extracts } & \multicolumn{7}{|c|}{ Pathogenic bacteria } \\
\hline & $\begin{array}{l}\text { Bacillus } \\
\text { subtilis }\end{array}$ & $\begin{array}{c}\text { Staphylococcus } \\
\text { aureus }\end{array}$ & $\begin{array}{c}\text { Micrococcus } \\
\text { leuteus }\end{array}$ & $\begin{array}{c}\text { Salmonella } \\
\text { setubal }\end{array}$ & $\begin{array}{c}\text { Pseudomonas } \\
\text { pickettii }\end{array}$ & $\begin{array}{c}\text { Escherichia } \\
\text { coli }\end{array}$ & $\begin{array}{l}\text { Sigella } \\
\text { flexneri }\end{array}$ \\
\hline Ciprofloxacin (Standard) & 0.75 & 0.187 & 0.75 & 0.187 & 1.50 & - & 0.375 \\
\hline QE & 0.187 & 1.50 & 1.50 & 0.187 & 1.50 & - & 1.50 \\
\hline $\mathrm{QHX}$ & 1.50 & 0.75 & 0.75 & 0.375 & 1.50 & - & - \\
\hline QCX & 0.75 & 1.50 & 0.187 & 0.375 & 0.187 & - & 0.75 \\
\hline ETX & 0.187 & 0.187 & 0.75 & 0.187 & 0.375 & - & 1.50 \\
\hline QBX & 1.50 & 1.50 & 0.375 & 1.50 & 0.75 & - & - \\
\hline
\end{tabular}

Each value in the table was obtained by calculating the average of three experiments.

TABLE 5 | Minimum inhibitory concentration values Antifungal activity of extract measured at different concentrations $(\mathrm{mg} / \mathrm{ml})$.

\begin{tabular}{lll}
\hline Plant extracts & \multicolumn{2}{c}{ Pathogenic fungi } \\
\cline { 2 - 3 } & A. flavus & A. niger \\
\hline QE & 0.187 & 1.5 \\
QHX & 1.50 & 0.375 \\
QCX & 0.75 & 0.187 \\
ETX & - & 1.5 \\
QBX & 0.75 & 1.50 \\
Nystatin (standard) & 0.375 & 1.50
\end{tabular}

Each value in the table was obtained by calculating the average of three experiments.

The high concentration of polyphenolic in the $n$-butanol fraction may be due to purification and concentration of phenolic, throughout the fractionation procedure and it is probably responsible for its high free RSA. n-Hexane fraction has least total phenolic content $43 \pm 4 \mathrm{mg} / \mathrm{g}$ as compared to other fractions. Different investigations of qualitative composition of plant extracts revealed, that high concentrations of phenols in the plant extracts obtained by using polar solvents (Canadanovic-Brunet et al., 2008). Therefore, the phenolic content of plant may contribute directly to their antioxidant action (Tosun et al., 2009).

\section{Antibacterial}

The secondary metabolites produced by medicinal plants constitute a source of bioactive substances and nowadays scientific interest has increased due to the search for new drugs of plant origin. The antibacterial activity of $Q$. incana Roxb. was shown in Table 4. In antibacterial activity, the $n$-butanol fraction was found significantly active against M. leuteus, Salmonella setubal and Pseudomonas pickettii bacterial strains. Ethyl acetate fraction was active against $M$. leuteus as compared to other strains (Figure 3). Chloroform fraction showed good activity against $P$. pickettii and moderately active against rest of strains. Similarly $n$-hexane and $n$-butanol fractions were active against all strain except Sigella flexneri. All fractions were found inactive against E. coli (Table 5).
TABLE 6 | Antifungal activity of $Q$. incana Roxb. (3 mg/ml, zone of inhibition in $\mathrm{mm} \pm S D$ ).

\begin{tabular}{lcc}
\hline Plant extracts & \multicolumn{2}{c}{ Pathogenic fungi } \\
\cline { 2 - 3 } & Aspergillus flavus & Aspergillus niger \\
\hline QE & $19 \mathrm{~mm} \pm 0.41$ & $18 \mathrm{~mm} \pm 0.85$ \\
QHX & $16 \mathrm{~mm} \pm 0.26$ & $19 \mathrm{~mm} \pm 0.41$ \\
QCX & $12 \mathrm{~mm} \pm 0.28$ & $14 \mathrm{~mm} \pm 0.66$ \\
ETX & - & $25 \mathrm{~mm} \pm 0.75$ \\
QBX & $28 \mathrm{~mm} \pm 0.45$ & $32 \mathrm{~mm} \pm 0.55$ \\
Nystatin (standard) & $16 \mathrm{~mm} \pm 0.92$ & $23 \mathrm{~mm} \pm 0.41$ \\
\hline
\end{tabular}

Each value in the table was obtained by calculating the average of three experiments.

The activities detected in the fractions of the Q. incana Roxb. suggest a synergistic action of some compounds, as well as the presence of other bioactive that are responsible for antibacterial activity.

\section{Antifungal Activity}

Reported literature showed that some species of genus Quercus showed immense antifungal activity against pathogenic strains (Serit et al., 1991). In current study, as shown in Table 6, $n$-butanol fraction showed promising activity against both strains (Aspergillus flavus and A. niger) while other fractions showed moderate activity against pathogenic fungal strains. Ethyl acetate fraction was inactive against A. flavus. Quercus species are famous for the presence of tannins exhibiting good antimicrobial activity (Cowan, 1999; Cushnie and Lamb, 2005).

\section{CONCLUSION}

The preliminary study carried out with Q. incana Roxb. showing its antimicrobial activity, total phenolic content, antioxidant, and NO scavenging activities encouraged us to continue chemical investigations in order to identify the active principles of this plant. The activities of extract and fractions of $Q$. incana Roxb. suggest the presences of synergetic action of some biological active compounds that may be present in the leaves of medicinal plant. The present 
studies will be provided an important clue for bio-assay guided isolation of new bioactive from this plant. Further studies are needed to better characterize the important active constituents responsible for the antimicrobial, antioxidant and free RSA.

\section{REFERENCES}

Adonizio, A. L., Downum, K., Bennett, B. C., and Mathee, K. (2006). Anti-quorum sensing activity of medicinal plants in southern Florida. J. Ethnopharmacol. 105, 427-435. doi: 10.1016/j.jep.2005.11.025

Bag, A., and Chattopadhyay, R. R. (2015). Evaluation of synergistic antibacterial and antioxidant efficacy of essential oils of spices and herbs in combination. PLOS ONE 10:e0131321. doi: 10.1371/journal.pone.0131321

Berahou, A., Auhmani, A., Fdil, N., Benharref, A., Jana, M., and Gadhi, C. A. (2007). Antibacterial activity of Quercus ilex bark's extracts. J. Ethnopharmacol. 112, 426-429. doi: 10.1016/j.jep.2007.03.032

Bobbarala, V., Vadlapudi, V. R., and Naidu, C. K. (2009). Antimicrobial potentialities of mangrove plant Avicennia marina. J. Pharm. Res. 2, 1019-1021.

Bredt, D. S., and Snyder, S. H. (1994). Nitric oxide: a physiologic messenger molecule. Annu. Rev. Biochem. 63, 175-195. doi: 10.1146/annurev.bi.63.070194.001135

Canadanovic-Brunet, J., Cetkovic, G., Djilas, S., Tumbas, V., Bogdanovic, G., Mandic, A., et al. (2008). Radical scavenging, antibacterial, and antiproliferative activities of Melissa officinalis L. extracts. J. Med. Food 11, 133-143. doi: 10.1089/jmf.2007.580

Choudhary, M. I., Begum, A., Abbaskhan, A., Musharraf, S. G., and Ejaz, A. (2008). Two new antioxidant phenylpropanoids from Lindelofia stylosa. Chem. Biodivers. 5, 2676-2683. doi: 10.1002/cbdv.200890221

Cowan, M. M. (1999). Plant products as antimicrobial agents. Clin. Microbiol. Rev. $12,564-582$.

Cushnie, T. P. T., and Lamb, A. J. (2005). Antimicrobial activity of flavonoids. Int. J. Antimicrob. Agents 26, 343-356. doi: 10.1016/j.ijantimicag.2005.09.002

Dawson, T. M., Dawson, V. L., and Snyder, S. H. (1992). A novel neuronal messenger molecule in brain: the free radical, nitric oxide. Ann. Neurol. 32, 297-311. doi: 10.1002/ana.410320302

Ge, H. M., Shen, Y., Zhu, C. H., Tan, S. H., Ding, H., Song, Y. C., et al. (2008). Penicidones A-C, three cytotoxic alkaloidal metabolites of an endophytic Penicillium Sp. Phytochemistry 69, 571-576. doi: 10.1016/j.phytochem.2007.07.014

Hamid, H., Kaur, G., Abdullah, S. T., Ali, M., Athar, M., and Alam, M. S. (2005). Two new compounds from the galls of Quercus infectoria. with nitric oxide and superoxide inhibiting ability. Pharm. Biol. 43, 317-323. doi: $10.1080 / 13880200590951711$

Haq, F., Ahmad, H., and Alam, M. (2011). Traditional uses of medicinal plants of Nandiar Khuwarr catchment (District Battagram), Pakistan. J. Med. Plants Res. 5, 39-48. doi: 10.1186/1472-6882-14-293

Harit, J., Barapatre, A., Prajapati, M., Aadil, K. R., and Senapati, S. (2013). Antimicrobial activity of rhizome of selected Curcuma variety. Int. J. Life Sci. Biotechnol. Pharm. Res. 2, 183-189.

Hussain, M., and Ghani, A. (2008). Herbal remidies used for gastrointestinal disorders in Kaghan valley, NWFP, Pakistan. Pak. J. Weed Sci. Res. 14, 169-200.

Ito, H., Yamaguchi, K., Kim, T. H., Khennouf, S., Gharzouli, K., and Yoshida, T. (2002). Dimeric and trimeric hydrolyzable tannins from Quercus coccifera and Quercus suber. J. Nat. Prod. 65, 339-345. doi: 10.1021/np010465i

Karioti, A., Bilia, A. R., Gabbiani, C., Messori, L., and Skaltsa, H. (2009). Proanthocyanidin glycosides from the leaves of Quercus ilex L. (Fagaceae). Tetrahedron Lett. 50, 1771-1776. doi: 10.1016/j.jep.2003.10.009

Kaur, G., Hamid, H., Ali, A., Alam, M. S., and Athar, M. (2004). Antiinflammatory evaluation of alcoholic extract of galls of Quercus infectoria. J. Ethnopharmacol. 90, 285-292. doi: 10.1016/j.jep.2003.10.009

\section{ACKNOWLEDGMENT}

We acknowledge Higher Education Commission (HEC) of Pakistan and COMSATS for financial support.

Konig, M., Scholz, E., Hartmann, R., Lehmann, W., and Rimpler, H. (1994). Ellagitannins and complex tannins from Quercus petraea bark. J. Nat. Prod. 57, 1411-1415. doi: 10.1021/np50112a010

Lai, L. S., Chou, S. T., and Chao, W. W. (2001). Studies on the antioxidative activities of Hsian-tsao (Mesona procumbens Hemsl) leaf gum. J. Agric. Food Chem. 49, 963-968. doi: 10.1021/jf001146k

Liu, R. H. (2003). Health benefits of fruit and vegetables are from additive and synergistic combinations of phytochemicals. Am. J. Clin. Nutr. 78, 517S-520S.

Marcocci, L., Maguire, J. J., Droylefaix, M. T., and Packer, L. (1994). The nitric oxide-scavenging properties of Ginkgo biloba extract EGb 761. Biochem. Biophys. Res. Commun. 201, 748-755. doi: 10.1006/bbrc.1994.1764

Moncada, S., Palmer, R. M., and Higgs, E. A. (1991). Nitric oxide: physiology, pathophysiology, and pharmacology. Pharmacol. Rev. 43, 109-142.

Nonaka, G. I., Nishimura, H., and Nishioka, I. (1985). Tannins and related compounds. Part 26. Isolation and structures of stenophyllanins A, B, and C, novel tannins from Quercus stenophylla. J. Chem. Soc. Perkin Trans. 1, 163-172. doi: 10.1039/P19850000163

Osawa, T., and Namiki, M. (1981). A novel type of antioxidant isolated from leaf wax of Eucalyptus leaves. Agric. Biol. Chem. 45, 735-739. doi: $10.1080 / 00021369.1981 .10864583$

Sati, S. C., Sati, N., and Sati, O. P. (2011). Chemical investigation and screening of antimicrobial activity of Stem Bark of Qurecus leucotrichophora. Int. J. Pharm. Pharm. Sci. 3, 89-91.

Serit, M., Okubo, T., Su, R. H., Hagiwara, N., Kim, M., Iwagawa, T., et al. (1991). Antibacterial compounds from Oak, Quercus acuta Thunb. Agric. Biol. Chem. 55, 19-23. doi: 10.1080/00021369.1991.10870529

Shibuki, K., and Okada, D. (1991). Endogenous nitric oxide release required for long-term synaptic depression in the cerebellum. Nature 349, 326-328. doi: $10.1038 / 349326 \mathrm{a} 0$

Shinwari, M. I., and Khan, M. A. (2000). Folk use of medicinal herbs of Margalla Hills National Park, Islamabad. J. Ethnopharmacol. 69, 45-56. doi: 10.1016/S0378-8741(99)00135-X

Tosun, M., Ercisli, S., Sengul, M., Ozer, H., Polat, T., and Ozturk, E. (2009). Antioxidant properties and total phenolic content of eight Salvia species from Turkey. Biol. Res. 42, 175-181. doi: 10.4067/S0716-976020090002 00005

Yamaguchi, T., Takamura, H., Matoba, T., and Terao, J. (1998). HPLC method for evaluation of the free radical scavenging activity of foods by using 1,1diphenyl-2-picrylhydrazyl. Biosci. Biotechnol. Biochem. 62, 1201-1204. doi: $10.1271 /$ bbb.62.1201

Zhou, L., van Heel, A. J., and Kuipers, O. P. (2015). The length of a lantibiotic hinge region has profound influence on antimicrobial activity and host specificity. Front. Microbiol. 6:11. doi: 10.3389/fmicb.2015.00011

Conflict of Interest Statement: The authors declare that the research was conducted in the absence of any commercial or financial relationships that could be construed as a potential conflict of interest.

Copyright (C) 2015 Sarwar, Farooq, Khan, Naz, Khan, Khan, Rauf, Bahadar and Uddin. This is an open-access article distributed under the terms of the Creative Commons Attribution License (CC BY). The use, distribution or reproduction in other forums is permitted, provided the original author(s) or licensor are credited and that the original publication in this journal is cited, in accordance with accepted academic practice. No use, distribution or reproduction is permitted which does not comply with these terms. 